PNL-SA--21302

DE93 004324

DIFFERENTIAL ELECTRON EMISSION IN MULTI-CHARGED ION-ATOM COLLISIONS: SYSTEMATIC FOR DISTANT AND CLOSE COLLISIONS

R. D. DuBois

L. H. Toburen

M. E. Middendorf

0 . Jagutzki

September 1992

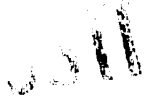

DEG I 4992

Presented at the Highly Charged Ion Conference September 27-October 2, 1992 Manhattan, Kansas

Prepared for the U.S. Department of Energy under Contract DE-AC06-76RLO 1830

Pacific Northwest Laboratory Richland, Washington 99352 


\title{
DIFFERENTIAL ELECTRON EMISSION IN MULTI-CHARGED ION ATOM COLLISIONS: SYSTEMATICS FOR DISTANT AND CLOSE COLLISIONS*
}

\author{
R.D. DuBois, L.H. Toburen, and M.E. Middendorf \\ Pacific Northwest Laboratory \\ Richland, WA 99352 USA \\ and \\ O. Jagutzki
}

Institute für Kernphysik der J.W. Goethe Universität Frankfurt

Frankfurt/M, D-6000 FRG

\begin{abstract}
Absolute doubly differential cross sections for electron emission are presented for $0.5 \mathrm{MeV} / \mathrm{u}$ multi-charged ion impact on helium, neon, and argon targets. For the helium target, $\mathrm{Bq}, \mathrm{Cq}+(\mathrm{q}=2-5)$ and $\mathrm{Oq}+\mathrm{Fq}+(\mathrm{q}=3-6)$ projectiles were studied; for neon and argon, only $\mathrm{Cq}+(\mathrm{q}=2-5)$ projectiles were used. Electron emission for $10^{\circ} \leq \Theta \leq 60^{\circ}$ was studied. The measured cross sections were assumed to scale as the square of an effective projectile charge, $Z_{\text {efl, }}$ which was determined as a function of emitted electron energy and angle. For distant collisions (low emitted electron energies), we find that $Z_{\text {elf }} \approx q$ for small $q$ and $Z_{\text {ell }}<q$ for the highest values of $q$ investigated. For sufficiently close collisions (above the binary encounter peak), $Z_{\text {ell }}=Z$ and increases as $q$ decreases. This is true for all angles and targets investigated.
\end{abstract}

\section{INTPODUCTION}

In ion-atom collisions, target ionization results from coulomb interactions between the target electron(s) and the projectile ion. Since the coulomb force is proportional to the projectile nuclear charge $Z$, the cross sections (which are proportional to the square of the force) are expected to increase as $Z^{2}$ for fast, fully stripped projectile impact. For structured projectile impacl, meaning projectiles with bound electrons of their own, the nuclear charge is partially screened by the bound electrons. Thus, within the Born theory, the target ionization cross sections will increase as the square of an effective projectile charge, $Z_{\mathrm{eft}}{ }^{2}$, which is a function of the momentum transfer. 1.2 This means that for distant collisions, i.e., small $k$ which generally means low energy electron emission, the screening is quite effective and the cross sections should scale as the square of the net lonic charge, $q$, independent of the nuclear charge $Z$. For very close collisions, i.e., large $k$ and therefore high energy electron emission, where the screening is relatively ineffective, only the nuclear charge should be 
important and the cross sections should scale as $\mathrm{Z}^{2}$, independent of the number of projectile electrons. These expectations are in accordance with data reported by Stolterfoht 3 for $2 \mathrm{MeV} / \mathrm{u} \mathrm{Oq+}-\mathrm{O}_{2}$ collisions.

Measurements of $0^{\circ}$ emission of fast electrons, i.e., in the binary encounter region, for various fully stripped lons ${ }^{4}$ have also confirmed the $Z^{2}$ scaling predictions. However, similar experiments for partially stripped ion impact demonstrate an "inverse q" scaling.5-7 By "inverse q" we mean that, for fixed $Z$ the binary peak intensity increases as $q$ decreases. This means that the cross sections for partially stripped projectiles are larger, not smaller, than those for fully stripped projectiles. This observation has since been explained by Reinhold el al. 8 and generalized by Schultz and Olson. 9 To date, however, all experimental studies demonstrating an inverse scaling effect have used $0^{\circ}$ electron emission and light $\left(\mathrm{H}_{2}\right.$ and $\left.\mathrm{He}\right)$ targets; but the theoretical work of Schultz and Olson predicts that the scaling depends on the angle of emision and no scaling should occur for electron emission at $=45^{\circ}$.

Thus we have performed a more systematic investigation of the differential electron emission where the following parameters were investigated. The projectile $Z$ was varied from 5 to 9 . The projectile charge state, $q$, was varied from 2 to 5 for $B$ and $C$ impact and from 3 to 6 for $O$ and $F$ impact. Selected angles of emission between 10 and $60^{\circ}$ were investigated. Various targets, namely $\mathrm{He}, \mathrm{Ne}$ and $\mathrm{Ar}$ were studied. In all cases, the impact energy was $0.5 \mathrm{MeV} / \mathrm{u}$ and the electron emission was studied from approximately 20 $\mathrm{eV}$ to energies well above the binary encounter peak. The purposes of this study were to investigate whether the scaling does indeed depend on the angle of emission as predicted and to investigate whether the differences between the "normal scaling as observed by Stolterfoht and the "inverse scaling" described above was possibly related to the laboratory emission angles used or to the target mass.

\section{PROCEDURE AND RESULTS}

These experiments were performed at the Pacific Northwest Laboratory where ion beams from a small tandem accelerator were stripped via interactions with a thin carbon foil, momentum analyzed, and then directed into the experimental apparatus. Because the stripper foil was located prior to the analyzing magnet, care was taken to clearly identify the charge state and ion velocity that entered the target region. The target chamber consisted of a directed atomic beam target and a shielded, rotatable, cylindrical-sector electron spectrometer and a channeltron detector. Magnetic fields inside the chamber were reduced to less than a few milligauss. The measured electron spectra were placed on an absolute scale by using a proton beam and 
normalizing to absolute cross sections previously measured in our laboratory.

In order to investigate how the cross sections scale with $Z$ and $q$, $Z_{\text {eff }}(\varepsilon, \Theta)$ was determined for each projectile $P$ and charge state $q$ from $Z_{\text {eff }}(\varepsilon, \Theta)=\left[25 \sigma(\varepsilon, \Theta)_{\mathrm{Pa}^{+}} / \sigma(\varepsilon, \Theta)_{\mathrm{B}^{5+}}\right]^{1 / 2}$, where $\varepsilon$ is the electron energy and $\sigma(\varepsilon, \Theta)_{\mathrm{pq}+}$

are the measured absolute, doubly differential cross sections.

We recognize that the boron data are influenced by capture to the continuum effects in the intermediate energy region, but chose this

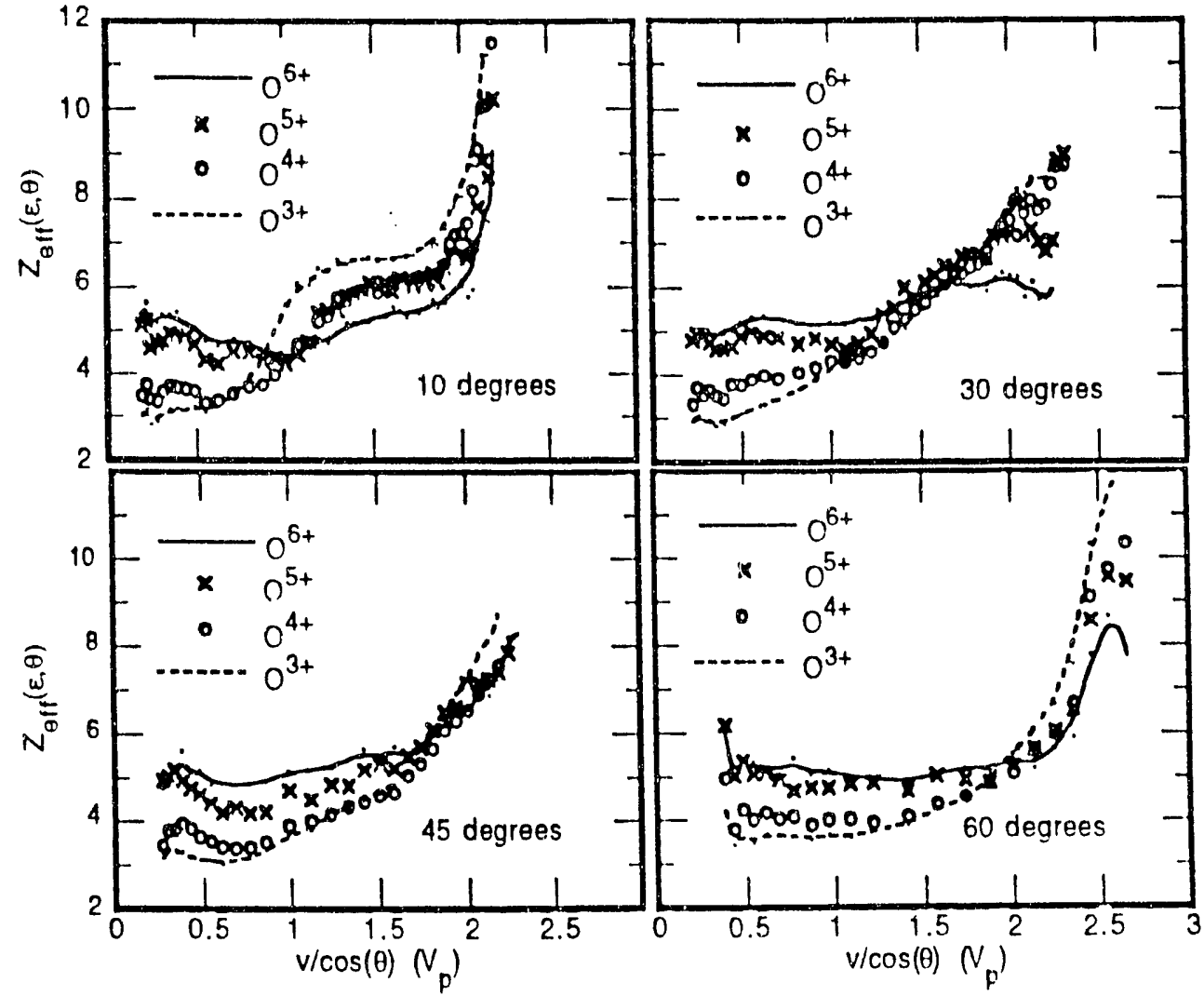

Fig. 1. $Z_{e f f}(\varepsilon, \theta)$ for $0.5 \mathrm{MeV} / \mathrm{u} \mathrm{Oq}+-\mathrm{He}$ collisions. approach to determine $Z_{\text {eff }}(\varepsilon, \Theta)$ since experinental uncertainties should cancel. Results for Oq+ impact are shown in Fig. 1 . In order to better compare $Z_{\text {eff }}(\varepsilon, \Theta)$ for different angles, the absissa is $v / \cos \Theta$ where $v$ is the electron velocity in units of the projectile velocity $V_{p}$. In these units, the binary peak occurs at $v / \cos \Theta=2$ while electron loss and capture to the continuum processes are at $v / \cos \theta=1 / \cos \Theta$.

The data show that for small electron velocities, i.e., for distant collisions, $Z_{\text {eff }}(\varepsilon, \Theta)=q$ for small $q$ but $Z_{\text {eff }}(\varepsilon, \Theta)<q$ for larger $q$. There is no apparant angular dependence. This behavior reflects how effectively the projectile nuclear charge is screened for distant collisions. For close collisions, specifically at the binary peak ( $v / \cos \Theta=2$ ), $Z_{\text {ell }}$ incieases with $q$ for small $\Theta$ but tends to be rather independent of $q$ for larger $\Theta$, just as predicted by Schultz and Olson. However, for closer collisions $(v / \cos \Theta>2) Z_{\text {eff }}$ is seen to always increase with decreasing $q$, for all projectiles and emission angles. 
Data obtained for heavier targets, namely for $\mathrm{Ne}$ and $\mathrm{Ar}$, generally demonstrate the same characteristics as those just discussed for $\mathrm{He}$. However, the inverse q scaling, although present, is less dramatic for these hearier targets. Thus this study indicates that an inverse q scaling of the cross sections always occurs provided that the collision is close enough. It is possible that the normal scaling observed by Stolterfoht occurs because the impact velocity is higher although the measurements described in ref. 5 extend to nearly the same impact energies and still demonstate an inverse scaling for close collisons. Hence an unresolved discrepancy remains.

\section{CONCLUSIONS}

This study has shown that for sufficiently close collisions, the differential cross sections systematically increase as electrons are added to a bare projectile ion. This appears to be independent of the emission angle and target, although the increase is more dramatic for $\mathrm{He}$ than for $\mathrm{Ne}$ and $\mathrm{Ar}$ targets. Trends indicated by the present data and previous studies performed at $0^{\circ}$ are in conflict with the measurements of Stolterioht and an unresolved discrepancy remains.

*Work supported in part by the Office of Health and Environmental Research, U.S. DOE, Contract No. DE-ACO6-76RLO-1830, the Willkomm-Stiftung and BMFT.

\section{References:}

1. JH McGuire, N Stolterioht and PR Simony, Phys Rev A 24, 97 (1981).

2. LH Toburen, N Stolterfoht, P Ziem and D Schneider, Phys Rev A 24, 1741 (1981).

3. N Stolterfoht, Structure and Collisions of lons and Atoms, ed IA Sellin (Berlin: Springer Verlag) p155 (1978).

4. DH Lee,k P Richard, TJM Zouros, JM Sanders JL Shinpaugh and H Hidmi, Phys Rev A 41,4816 (1990).

5. P Richard, DH Lee, TJM Z.ouros, JM Sanders and JL Shinpaugh, J Phys B 23, L213 (1990).

6. O Jagutzki, S Hagmann, H Schmidt-Böcking, RE Olson, DR Schultz, R Dörner, R Koch, A Skutlartz, A Gonzalez, TB Quinteros, C Kelbch and P Richard, J Phys B 24, 2579 (1991).

7. TB Quinteros, AD Gonzalez, O Jagutzki, A Skutlartz, DH Lee, S Hagmann, $P$ Richard, $C$ Kelbch, SI Varghese and H Schmidt-Böcking, J Phys B $\underline{24}$, 1377 (1991).

8. CO Reinhold, DR Schultz and RE Olson, J Phys B 23, L591 (1990).

9. DR Schultz and RE Olson, J Phys B 24, 3409 (1991). 


\section{DISCLAIMER}

This report was prepared as an account of work sponsored by an agency of the United States Government. Neither the United States Government nor any agency thereof, nor any of their employees, makes any warranty, express or implied, or assumes any legal liability or responsibility for the accuracy, completeness, or usefulness of any information, apparatus, product, or process disclosed, or represents that its use would not infringe privately owned rights. Reference herein to any specific commercial product, process, or service by trade name, trademark, manufacturer, or otherwise does not necessarily constitute or imply its endorsement, recommendation, or favoring by the United States Government or any agency thereof. The views and opinions of authors expressed herein do not necessarily state or reflect those of the United States Government or any agency thereof. 

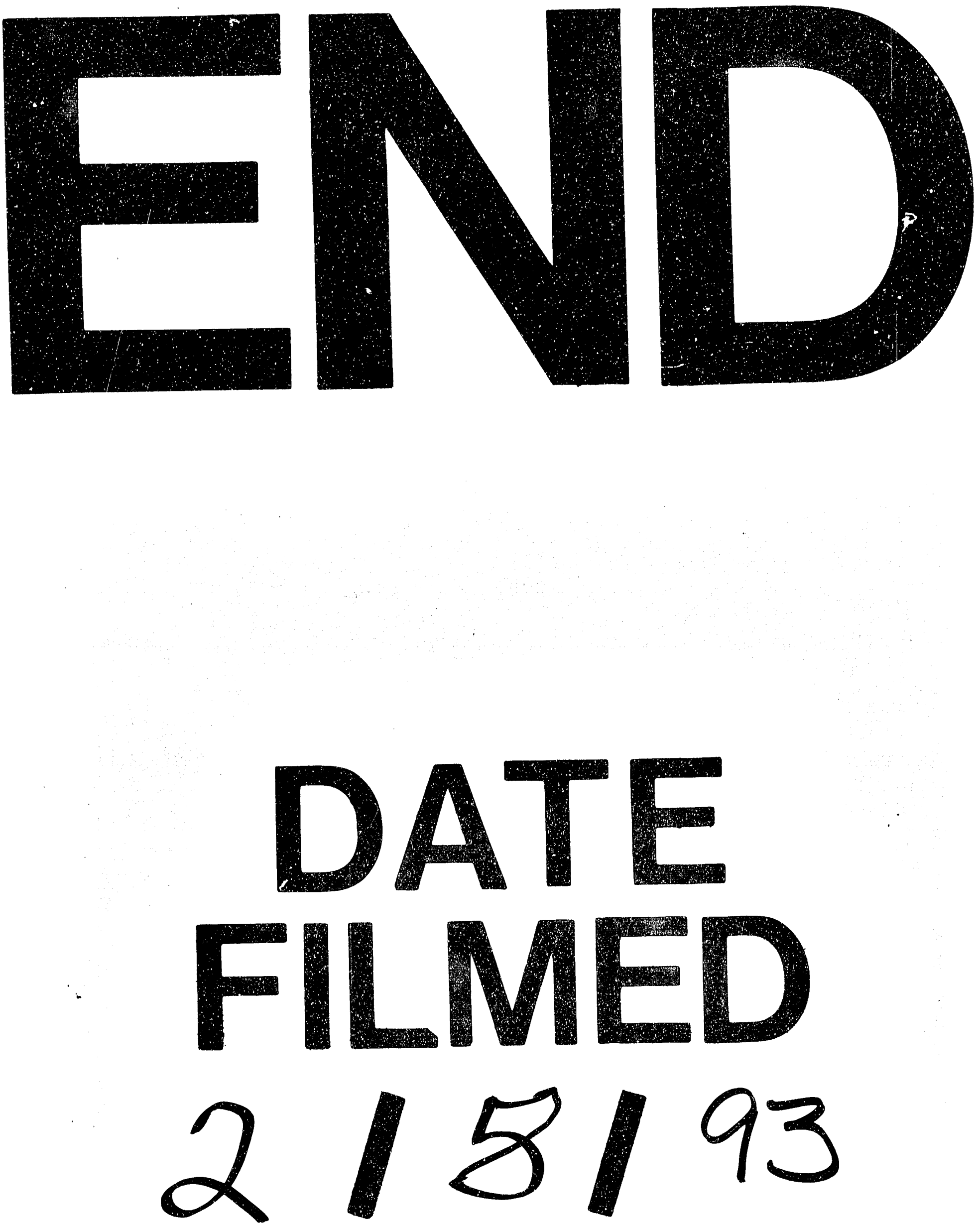
